\title{
The in vivo regulation of pulsatile insulin secretion
}

\author{
N. Pørksen ${ }^{1}$ \\ ${ }^{1}$ Medical Department of Endocrinology and Metabolism, Aarhus University Hospital, Noerrebrogade, 8000 Aarhus C, Denmark
}

\section{Abstract}

The presence of oscillations in peripheral insulin concentrations has sparked a number of studies evaluating the impact of the insulin release pattern on the action of insulin on target organs. These have convincingly shown that equal amounts of insulin presented to target organs have improved action when delivered in a pulsatile manner. In addition, impaired (not absent) pulsatility of insulin secretion has been demonstrated in Type II (non-insulin-dependent) diabetes mellitus, suggesting a possible mechanism to explain impaired insulin action in Type II diabetes. Whereas the regulation of overall insulin secretion has been described in detail, the mechanisms by which this regulation affects the pulsatile insulin secretory pattern, and the relative and absolute contribution of changes in the characteristics of pulsatile insulin release have not been reviewed previously. This review will focus on the importance of the secretory bursts to overall insulin release, and on how insulin secretion is adjusted by changes in these secretory bursts. Detection and quantification of secretory bursts depend on methods, and the methodology involved in studies dealing with pulsatile insulin secretion is described. Finally, data suggest that impaired pulsatile insulin secretion is an early marker for beta-cell dysfunction in Type II diabetes, and the role of early detection of impaired pulsatility to predict diabetes or to examine mechanisms to cause beta-cell dysfunction is mentioned. [Diabetologia (2002) 45: 3-20]

Keywords Insulin, pulsatility oscillation, diabetes, physiology, secretion, regulation, $\mathrm{C}$ peptide.
In 1922, Karen Hansen [1] measured two series of blood glucose concentrations and reported oscillations in the peripheral concentrations of this substrate, results which were validated by simultaneous sampling from two sites to exclude the possibility

Received: 9 November 2000 and in revised form: 26 July 2001

Corresponding author: N. Pørksen, Medical Department of Endocrinology and Metabolism, Aarhus University Hospital, Noerrebrogade, 8000 Aarhus C, Denmark

(e-mail: porksen@dadlnet.dk)

Abbreviations: ApEn, Approximate entrophy; LH, luteinizing hormone; ACTH, adrenocorticotropin; GABA, gamma-amino-butyrate; GLP-1, glucagon-like-peptide-1; IGF-1, insulinlike-growth-factor-1; IGF-BP1, insulin-like-growth-factor-1binding-protein that assay variability was a cause of the observed variations. Furthermore she studied the glucose concentrations in diabetic patients, and described both rapid and slower oscillations [1]. Half a century later the observation of rapid oscillations was shown to correlate with oscillations in the peripheral insulin concentrations [2-6], with glucose concentration increases slightly out of phase with insulin secretion pulses [7]. The pulsatile secretion of insulin was shown to coincide with islet pulsatile release of glucagon $[4,6,8$, 9], and somatostatin [9-11]. A number of studies have reported importance of this release pattern for optimal insulin action [10,12-21, 21-25], for overall insulin secretion [26-35], and for possible development of disease [36-43]. Studies on pulsatile insulin secretion could therefore be important for appreciating how insulin release is regulated overall and how 
the underlying mechanisms impact on insulin action. Once the physiology of pulsatile insulin release processes is understood, this knowledge could be employed to analyse defects in disease states, and on a mechanistic basis to evaluate different hypotheses of the cause of the defects observed at disease.

In addition to the rapid pulsatile insulin release pattern, an ultradian oscillatory pattern has been described [44-50], and associated with improved insulin action [46, 51, 52], and, in case of impairment, with Type II (non-insulin-dependent) diabetes mellitus [44, 45, 47-49], and early Type I (insulin-dependent) diabetes mellitus [53]. Finally, diurnal (meal related) oscillations are an apparent [54-58] and, probably, an important [47] contributor to the complexity of insulin release, that assures normal physiological release to meet the needs of glucose homeostasis.

This review will mainly focus on the rapid oscillatory insulin secretory pattern, and will relate the observations of in vivo pulsatility to important aspects of oscillatory beta-cell function reported in vitro.

\section{Impact of pulsatile insulin secretion on insulin action}

The demonstration of pulsatile insulin secretion has lead to a number of studies that specifically addressed the importance of this insulin release pattern on insulin action. The target organs are mainly liver, muscle and adipose tissues. Studies have been designed to assess the impact of insulin release patterns on each of these insulin sensitive target organs. Anatomically, the most obvious candidate organ for a pulsatile versus constant release is the liver. Because insulin is released into the portal vein, any change in insulin secretion will cause changes of portal vein insulin concentrations. Through fenestrated sinusoids and the space of Disse, these changes will result in changes in the concentrations that the hepatocytes see and impact on liver metabolism. . The impact of pulsatile versus constant insulin delivery on hepatic insulin action is improved when insulin is presented to the liver in a pulsatile manner. Because portal vein insulin delivery is hard to control in vivo, studies on the isolated perfused liver are needed, and in these studies, specifically designed to address this, an improved ability to suppress glucagon-induced hepatic glucose production has been reported when insulin is delivered in a pulsatile manner [59]. Similarly, in Type I diabetic patients, a model to evaluate insulin actions without confounders from other hormones, showed that hepatic glucose production was reduced by $25-30 \%$ when the same amounts of insulin were delivered in a pulsatile rather than constant way [23]. The improved insulin action could be attributed to insulininsulin receptor kinetics, where insulin binding causes internalization of the insulin receptor for a brief period, allowing it to resurface before the next insulin secretory burst arises. This could explain why the impact of pulsatile delivery is frequency-dependent [16].

In contrast, pulsatile insulin delivery has not been reported to change [60] or improve peripheral glucose uptake $[12,18,20,21,23,24]$. Furthermore, adipose tissue shows improved insulin sensitivity when insulin is administered in a pulsatile fashion $[12,13]$ as reviewed previously $[19,61]$. Conversely, the insulin secretory pattern is associated with changes in insulin sensitivity $[12,13,62,62]$ and is altered in the elderly $[63,64]$. Effects of pulsatile insulin delivery on glucose uptake in insulin-sensitive tissues seem to require some time to occur, and most studies have been extended to 6 or $7 \mathrm{~h}$ to show a difference. Considering the rather quick effects on liver metabolism in the open loop isolated perfused liver, a direct effect on the liver and an indirect effect on peripheral glucose metabolism could be possible. This also seems likely considering the very dampened insulin oscillations that occur once insulin reaches muscle insulin receptors. The amplitude is about $30 \%$ in the arterial circulation, and before reaching the muscular or adipose tissue beds, the insulin signal needs to cross the capillaries and diffuse to the target organ, thus further reducing the relative signal (pulse amplitude). Furthermore, the recent emphasis on muscle lipid content to cause insulin resistance supports this notion.

The improved insulin action with physiologically pulsatile insulin delivery has further underscored the importance of impaired insulin pulsatility in Type II diabetes whose hallmark is impaired insulin action. Therefore, strategies to affect beta-cell function in Type II diabetes could influence insulin action, by the same mechanisms by which the oscillatory insulin release is affected.

\section{Methods for assessing pulsatile insulin secretion}

There are different reasons for assessing pulsatile insulin secretion, and the method for analysis has to be chosen accordingly. In general the secretion is determined using concentrations of either insulin or Cpeptide. For this reason, to detect a secretory burst and to prevent the detection of assay or biological variability as secretory pulses, it is crucial to optimize the methods involved in sampling, concentration measurements and data analysis to discriminate between signal and background noise.

Sampling site. Insulin is secreted into the portal vein circulation, and undergoes partial (40 to $80 \%$ [65-68]) hepatic extraction before dilution into the systemic insulin pool. Detection of pulsatile insulin release is further hampered by a time-delayed dampening of the insulin pulses [69]. Portal-vein sampling 


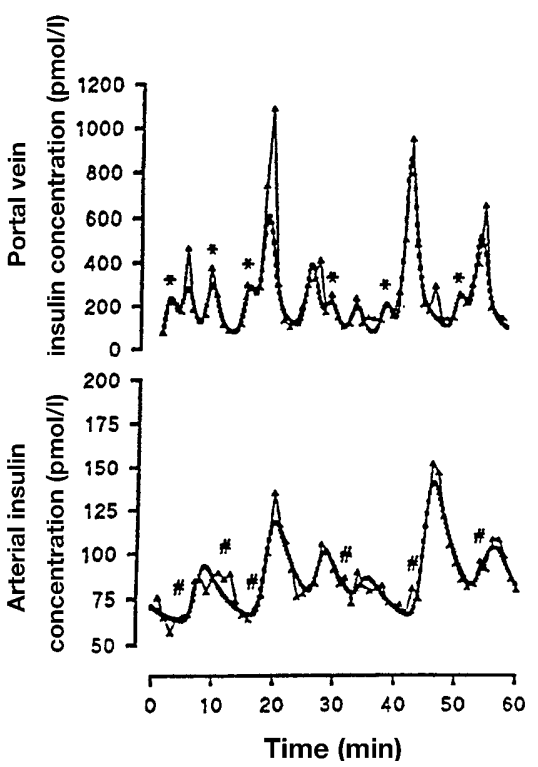

Fig. 1. Simultaneously measured portal vein (top panels), and arterial (bottom panels) insulin concentration time series, at overnight fasting conditions in a dog. The full line shows the concentration profile that arises from deconvolution analysis, assuming detection of distinct secretory bursts, superimposed on time invariant basal insulin release. Note that in the peripheral circulation (bottom panels) some of the secretory bursts detected in the portal vein $(*)$ are missing, although inspection of raw data suggests the presence of overlapping pulses (\#). This is highlighted in the right side panels demonstrating three portal vein pulses that merge into one three-phasic pulse in the peripheral circulation $(1,2,3)$

can overcome most of the pulse detection problems referred to above (Fig. 1; and Fig. 2). In animal models, short-term (hours) and chronically (weeks) implanted portal-vein catheters have been used for sampling purposes, providing an opportunity for applying portal-vein sampling to studies on in vivo pulsatile insulin release [26, 69, 70]. Sampling from the portal vein results in an increase in the insulin concentration oscillations from approximately $30 \%$ in the peripheral circulation to 80 to $500 \%[26,69]$ in the portal vein and consequently the ratio of signal (pulse oscillations) to noise (assay variability, dilution by saline flush, variable protease degradation of insulin in samples etc) is markedly improved with portal-vein sampling. This has been achieved in humans [71] and could be used specifically for those who need an implantation of transjugular intrahepatic portosystemic shunt $[72,73,73]$.

Sampling intensity and duration. Traditionally sampling every minute $[4,5,10,14,26-29,34-37,43,69$, 73] or every second minute $[3,13,15,33,74-76]$ for $1-2 \mathrm{~h}$ has been done to study the rapid insulin oscillations. Sampling from the portal vein or a peripheral

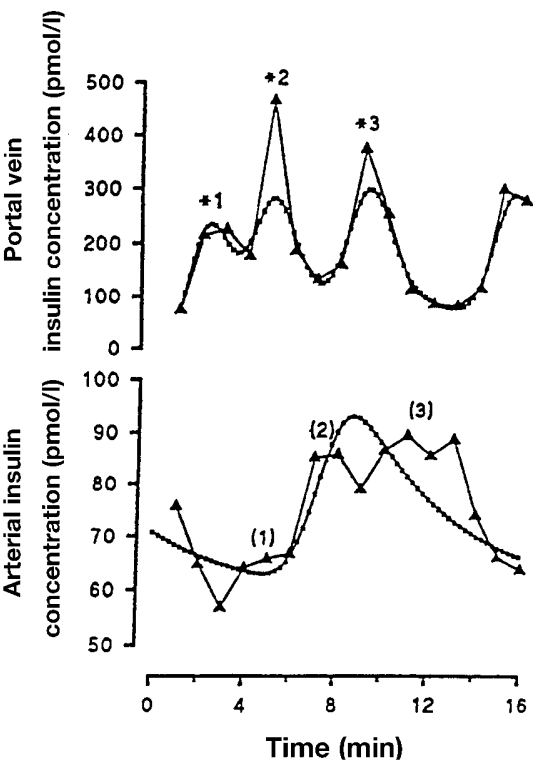

vein for insulin measurements every $30,60,120$, and $240 \mathrm{~s}$ demonstrates a decrease in pulse detection when the sampling intensity is reduced from $60 \mathrm{~s}$ for each sample $[26,69]$. Furthermore, there is a tendency for fewer pulses to be detected in those studies sampling every second as opposed to every minute (Table 1) (Figure 3). In contrast, no further improvement of the pulse detection has been achieved by sampling every $30 \mathrm{~s}[26,69]$. The high frequency sampling and replicate measurements are costly so sampling duration should be short. The repetitive nature of pulsatile insulin secretion $[4,5,10,33,76]$ would allow a reliable measurement of pulse frequency and amplitude using a sampling duration of 40 to $60 \mathrm{~min}$ [69] if deconvolution analysis or simple pulse detection algorithms are used. However, analysis based on autocorrelation (minimum 2 times pulse interval) and on spectral analysis $(n>100)$ as well as regularity statistics (approximate entropy: $n>40$ ) in general improve with increased sampling duration and therefore most studies using periodicity statistics are carried out over a longer duration $[4,5,10,33,76]$.

Insulin versus C-peptide measurements. Insulin and C-peptide are co-released in a 1 to 1 molar ratio [77]. Whereas insulin undergoes substantial (40-80\%) and variable [66, 78-80] hepatic-insulin extraction [81], C-peptide is presumably not cleared by the liver [82], which resulted in a predominance of the use of C-peptide when calculating the overall insulin secretory rates. C-peptide kinetics are similar under different conditions and thus suited for a comparison of insulin release among different groups [83]. However, the half-life of C-peptide is markedly longer ( $~ 35 \mathrm{~min}$ ) [83] than the half-life of insulin (5-8 min) [35], and this longer half-life of C-peptide will dampen oscillations and reduce signal to noise ratio oscillations correspondingly and result in an improved de- 


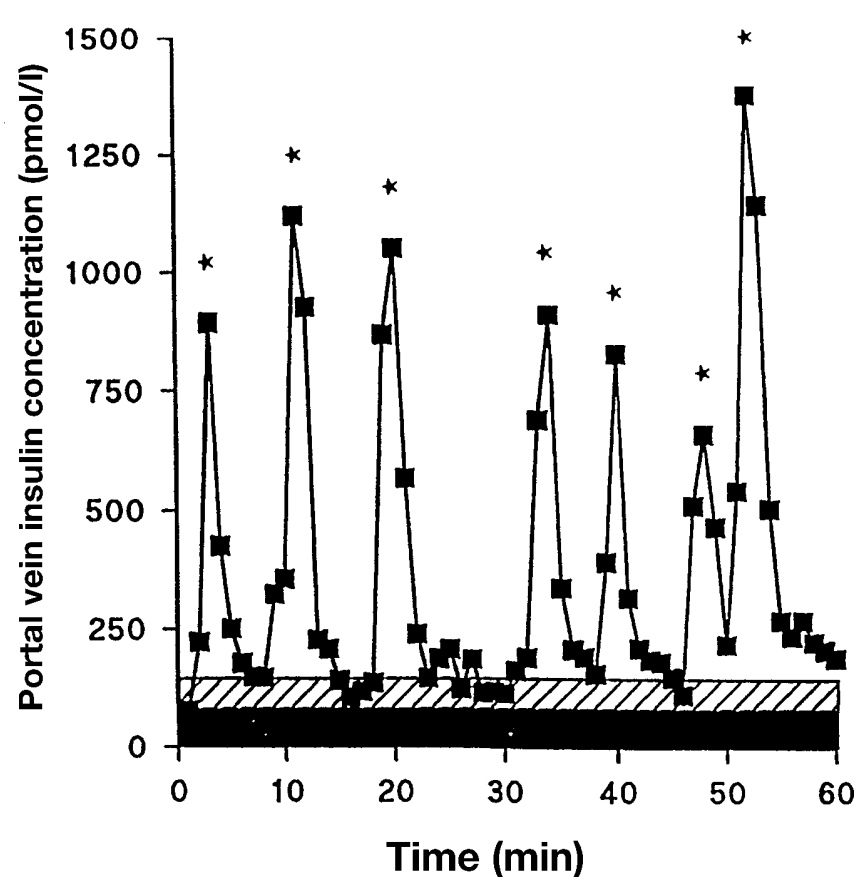

Fig. 2. Portal vein insulin concentrations in an overnight fasted dig. Note the very large insulin pulses. The hatched and solid areas are arterial insulin concentrations (measured every $10 \mathrm{~min}$ ) showing that between pulses, no insulin is released in such a case

tection of secretory bursts by use of insulin as opposed to C-peptide measurements. Amylin, which has been shown to have synchronous oscillations in the peripheral circulation [84], and a combined analysis of insulin with amylin or C-peptide or both could improve the analytical ability to detect coordinate secretory events.

Assay and biological noise. Sampling could involve some variability because saline infusion and flushing could be necessary to assure sampling catheter patency, resulting in dilution, which can be minimized through dead-space withdrawal. During and following the sampling process a variable haemolysis could occur, and proteases could be involved in degrading insulin in syringes and tubes, a process referred to as biological noise [69]. Measurements of insulin concentrations are also subject to assay variability, and a reliable, sensitive and specific assay is crucial to minimize the variability due to measurements. Considered together, the noise from sampling and assay procedures should be compared to the biological signal detected because concentrations change due to the pulsatile release. This supports the use of portal-vein sampling with improved signal but also highlights the necessity to optimize sampling and analysis of blood for insulin concentrations. A specific problem with assays can be the detection of pro-insulin, which has a longer half-life, and occurs at greater concentrations in the circulation in early Type II diabetes $[85$,
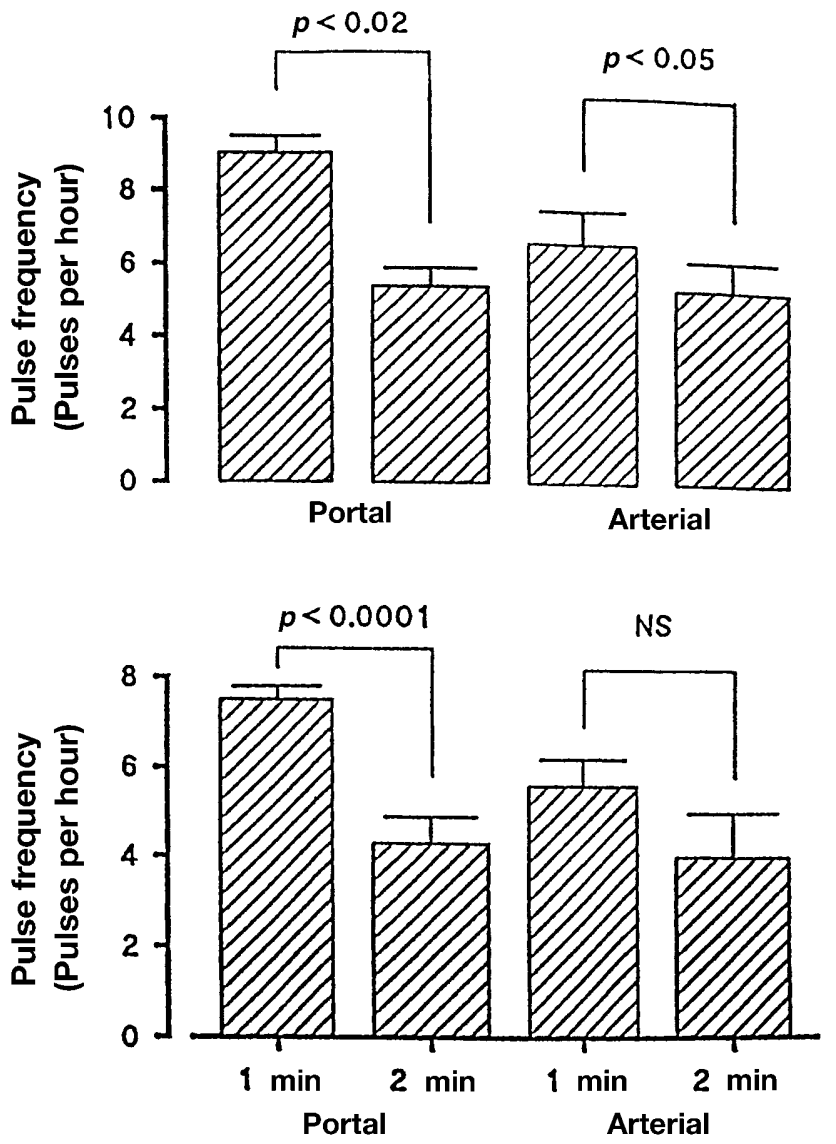

Fig.3. Detected pulse frequency by deconvolution analysis (top panel) and by cluster analysis (bottom panel) when sampling every $1 \mathrm{~min}$ comparing with every $2 \mathrm{~min}$ in the portal vein (left) rather than the artery (right)

86] and at states with beta-cell loss [87]. Therefore, to discriminate between pathophysiology in Type II diabetes and states of impaired beta-cell function, the use of an assay that does not cross react with pro-insulin is helpful.

Analytical strategy. The problems with biological time series are often connected with the presence of trends and noise.

Trends and subtrends. An analytical strategy needs to be chosen to address the question asked (i.e. what is the frequency that is examined for). The influence of subpatterns on high frequency oscillations can be avoided by detrending as with first differencing, or analysis of residuals after subtraction of a fitted line employing linear regression, for example, by moving average or other models to fit the data curve. The solution to the problem of noise could be a low pass filter as with smoothing procedures, where the chosen window lengths and weighing of data points could be important for the outcome. These procedures affect the specific patterns in the data to be examined. When several patterns occur together techniques 
Table 1.

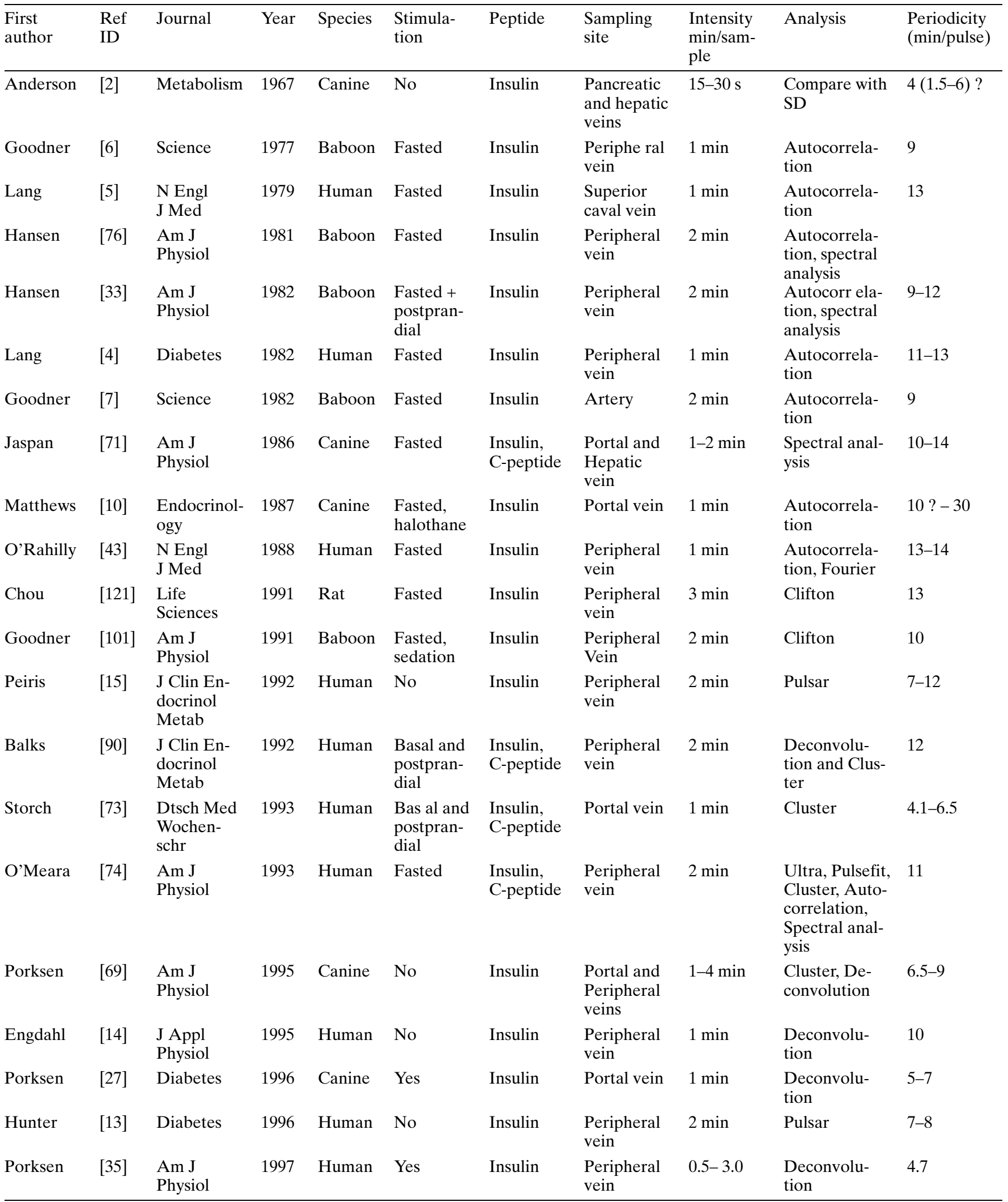


could be used to separate these patterns and evaluate them independently [36]. The rapid and ultradian insulin oscillations data set could contain periodicities of about 7 and $120 \mathrm{~min}$, and at minutely sampled intervals the slower ultradian oscillations could be detrended by first differencing the data, or by subtracting a moving average that is close to the frequency studied (i.e. for insulin 7-11 point moving average), before analysing for the rapid frequency pattern. In contrast, smoothing procedures by $3-11$ point moving average tend to remove signals of the rapid frequency. Inspection of raw data before any filtering procedure to allow time for readers to gain intuitive impressions of data signals and see the raw data.

Pulse detection. Analysis of peripheral insulin concentrations can give rise to detection of the individual concentration pulses and valleys ("basal concentrations"), and subsequently mean relative and absolute amplitudes and mean frequency. This detection method is based on predetermined statistical criteria to allow concentration changes to be considered significant; this approach is the basis of well established methods, such as Pulsar [8, 13, 71, 88] and Cluster analysis $[69,89,90]$, and ULTRA $[74,75,91]$. The drawback is that each concentration change has to pass the significance criteria to be detected, and relative low biological signals might not be detected, as well as impairment of pulse detection due to frequency increase, which is a possible problem, when increasing frequency of pulses tend to cause overlap. Due to low signal-to-noise ratio, the estimated pulse frequency decreases to the extent that pulses are not detected. The method will quantify the secondary concentration events.

Periodicity analysis. The frequency of the insulin pulses can be estimated by spectral analysis, or autocorrelation analysis which evaluates the concentration time series for regular periodicities. Spectral analysis may be rather unaffected by noise because more random data variability will probably not influence the detected periodicity. The ability to estimate if the spectral power in a single data set reflects significant periodicity can be estimated by observing analysed data and subsequently subjecting it to random shuffling before re-analysis giving a mean spectral power and SD of randomly distributed values, allowing comparison of observed spectral density to data obtained from randomly distributed data. Autocorrelation analysis also detects periodicity in data. The method examines replicability of patterns. The method will give frequency of concentration changes, significance for this pattern, and a correlation coefficient. However, these two methods are restricted to the evaluation of periodicities of peripheral concentration changes and do not directly give information on secretion apart from a likely estimate of the fre- quency of the insulin secretory bursts. Lack of significant periodicities can be due both to large variability in frequency or amplitude of truly present secretory bursts, which can be detected by pulse detection algorithm, or they can be due to relatively small pulses occurring at a regular interval. The latter could in part be overcome by increasing sampling duration.

Regularity statistics. The pulsatile insulin release pattern could also be characterized in further detail to examine the reproducibility of the subordinate patterns in the data set. A validated mathematical approach is application of approximate entropy (ApEn) [36, 92-94]. Approximate entropy is a recently introduced regularity statistics that measures the logarithmic likelihood that runs of patterns will be reproduced on next incremental comparison. The method has proved to be useful in a number of studies on hormonal secretion including growth hormone [95], LH [96], aldosterone [97], cortisol and ACTH $[98,99]$, and recently insulin $[36,64]$ to discriminate between pathophysiology and health. The method is robust to noise and to absolute differences in data. Derived values from approximate entropy analysis do not provide information on basal secretion, pulse mass/amplitude or frequency.

Detection and quantification of pulsatile insulin secretion by deconvolution. Insulin concentration time series can be analysed by deconvolution to detect and quantify insulin secretory bursts. Deconvolution of insulin concentration data can be carried out with a multi-parameter technique [100]. This requires the assumption that insulin concentrations measured in samples collected at known intervals result from five determinable and correlated parameters. These are, (i) a finite number of discrete insulin secretory bursts occurring at specific times and (ii) having individual amplitudes (maximal rate of secretion attained within a burst); (iii) a common half-duration (duration of an algebraically Gaussian secretory pulse at half-maximal amplitude), which is superimposed upon; (iv) a basal time-invariant insulin secretory rate; and finally, a bi-exponential hormonal (C-peptide/insulin) disappearance model in the systemic circulation with known or estimated half-lives. Assuming the foregoing hormonal disappearance values, the number, locations, amplitudes and half-duration of insulin secretory bursts, as well as a non-negative basal insulin secretory rate for each data set is estimated by non-linear least-squares fitting of the multi-parameter convolution integral for each insulin time series. Insulin secretion calculated by use of C-peptide concentrations is more robust to intra-individual and inter-individual variation in kinetic parameters [83]. When doing deconvolution analysis it is important to adjust basal secretion to allow accommodation of troughs. Deconvolution involves subjective elements, 
although defined peaks are tested for significance and all data analysis must be done in a blinded manner. The technique requires no assumptions about frequency, amplitude and stationarity.

\section{Contribution of pulsatile insulin release to the overall insulin secretion}

Peripheral insulin concentrations oscillate [2-6], because of pulsatile insulin secretion [3]. However, the net contribution of the secretory bursts is important, because the presence of concentration oscillations does not exclude the dominance of a time-invariant (basal) release pattern. Furthermore, the relation between the in vivo observed secretory bursts and the in vitro observed pulsatile release from the isolated pancreas $[9,10,101]$ and the isolated peri-perfused islets [102,103], as well as episodic beta-cell depolarization [104-106], beta-cell glycolysis [105, 107], and beta-cell increase in calcium remains to be established [104, 105, 108-111]. The coupling of cyclic metabolism to pulsatile in vitro release has been addressed in an excellent review by Tornheim [112]. Mathematical models have been used to better understand the mechanisms underlying coordinate pulsatile release $[113,114]$. Comparisons of exact measures of secretory burst shape, duration, frequency and secretory process orderliness of in vitro and in vivo insulin secretory bursts could further underline the link between intracellular beta-cell events, to large amplitude in vivo pulsatile insulin release.

Configuration. If an in vivo pulse consists of the summation of about one million simultaneous insulin secretory bursts from individual islets then a similar burst shape and duration is to be expected. In contrast, a broader in vivo than in vitro pulse configuration is expected if the in vivo pulse consists of the summation of release from islets that secrete at different times, because each islet in itself has a secretory burst duration of 2 to $3 \mathrm{~min}$ [115]. If therefore, the shapes of the individual secretory bursts from individual islets and from in vivo secretion are super-imposible (corrected for amplitude) then this suggests that the in vivo pulse is generated by simultaneous secretion from the intra-pancreatic islet population (Fig.4). Comparisons between human in vivo [26, $35]$ and in vitro [105] pulse shape suggests that the in vivo pulse reflects simultaneous secretion from all islets.

Frequency. A large variety of frequencies of in vivo pulsatile insulin secretion has been reported, varying from 4 to 15 min per pulse (Table 1 ). In contrast, the in vitro periodicity from the isolated perfused pancreas has been reported to be 6-10 min per pulse $[8-10,39,116]$. The latter are not confounded by he-
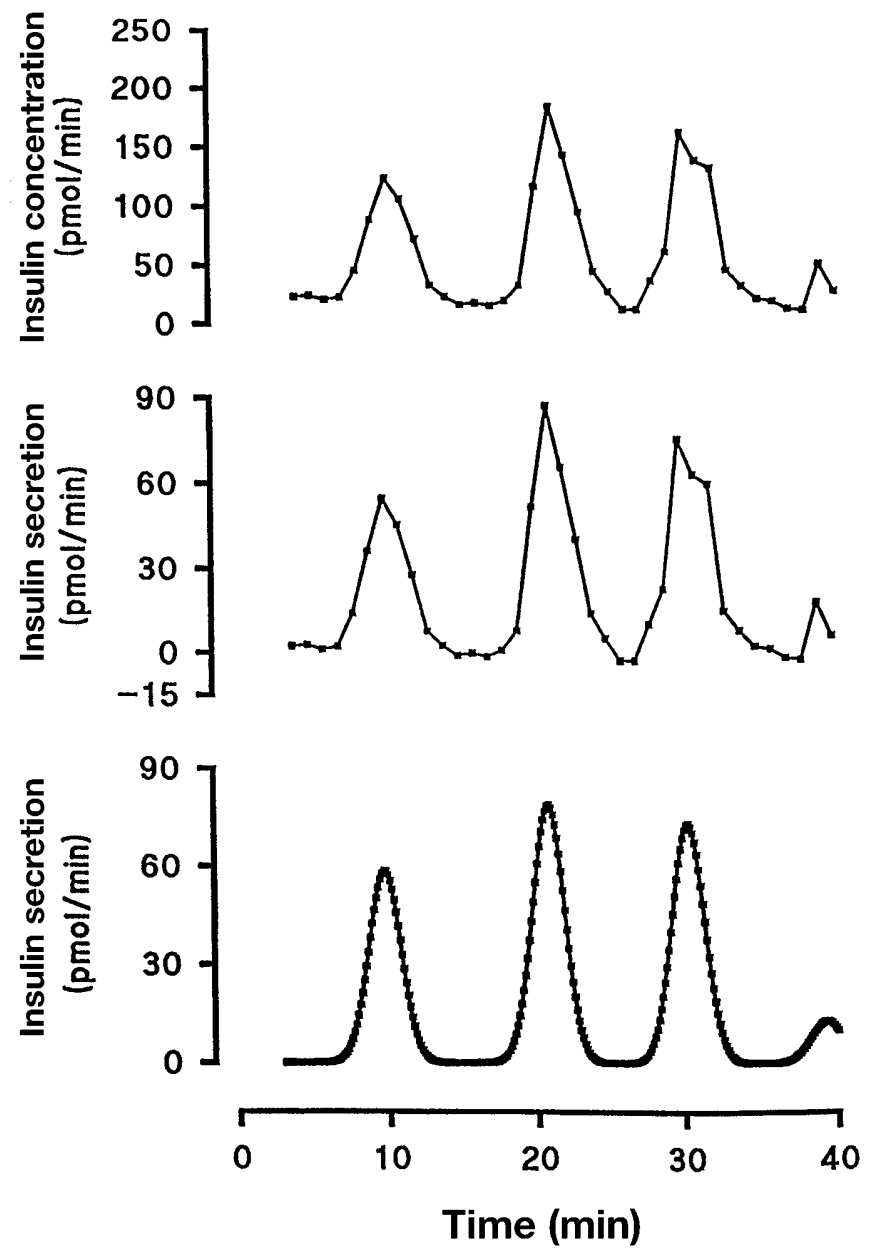

Fig. 4. Measured portal-vein insulin concentrations (top panel) and calculated insulin secretory rates from deconvolution analysis (bottom panel) and by cross-pancreatic sampling, multiplying by portal-vein plasma flow. Note that in this case no basal (non-pulsatile) insulin secretion is detected and this is observed very clearly by both methods independently

patic insulin extraction or dilution into the systemic insulin pool to make pulse detection easier. Similarly, studies on pancreas-transplanted subjects with shunts from the pancreas to the inferior caval vein, show increases in frequency versus healthy controls (8 versus $12 \mathrm{~min}$ per oscillation) [75]. Finally the reported frequency of 3 to 5 min per pulse in the isolated perifused islet $[105,115,117,118](10-17$ min per pulse in $[102,119,120])$, suggests that there is a hierarchy of regulatory mechanisms with the fastest frequency in individual islets ( 3 to $5 \mathrm{~min}$ ), followed by the perfused pancreas $(6-10 \mathrm{~min})$ and finally the in vivo insulin secretion ( 5 to $15 \mathrm{~min}$ ). However, the open loop systems usually employed in in vitro rather than the closed loop system in vivo, with confounding effects of systemic dilution and hepatic insulin extraction, could cause a relatively low estimate of the in vivo pulse frequency. Studies comparing sampling intensities, sampling sites and mathe- 


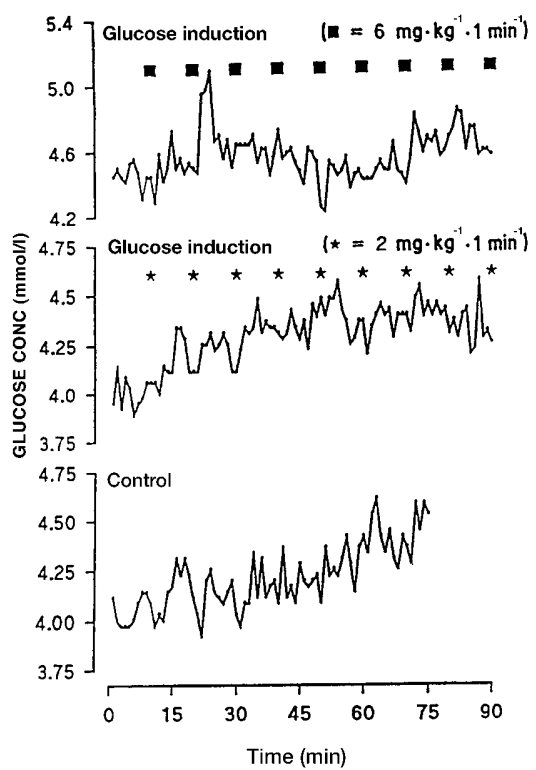

Fig. 5. Glucose (left panels) and insulin (right panels) when pulsatile insulin secretion was controlled (entrained) by punctuate glucose infusions over $1 \mathrm{~min}$ giving $6 \mathrm{mg} / \mathrm{kg}$ over $1 \mathrm{~min}$ (top panels), or $2 \mathrm{mg} / \mathrm{kg}$ over $1 \mathrm{~min}$ (middle panel, every 10 min starting at time $10 \mathrm{~min}$, compared with basal (non-entrained) concentrations in the bottom panels. Note the large apparent amplitude of peripheral insulin oscillations occurring with each glucose infusion, despite very minimal glucose excursions in the top panel and a more irregular pattern in the middle and bottom panels

matical strategies for the detection of insulin secretory bursts, suggest that studies sampling every $2 \mathrm{~min}$ and pulse detection analysis tend to underestimate the frequency, when secretory bursts tend to overlap $[13,15,33,74,121]$. Portal-vein sampling in dogs [27, 69], and in humans [73], shows a frequency of secretory bursts of approximately 6 min per pulse. A similar frequency is detected using a new insulin ELISA technique on minutely sampled peripheral blood, and using deconvolution [35]. It thus appears that refined sampling protocols and highly sensitive analytical tools, yield a periodicity of about $6 \mathrm{~min}$. This is similar to the frequency observed in the isolated perfused pancreas $[8-10,39,116]$ and suggests that the pacesetting mechanism resides within the pancreas and is not a circulating or central nervous system controlled mechanism and that frequency could be reduced by in vivo operating mechanisms. Yet it has still convincingly been shown in other studies, that a periodicity of about 13 min occurs at some states (see Table 1), and the question of periodicity is not well established.

Overall contribution. To assess the contribution of pulsatile to overall insulin secretion it is necessary to measure or calculate the pulsatile and time-invariant

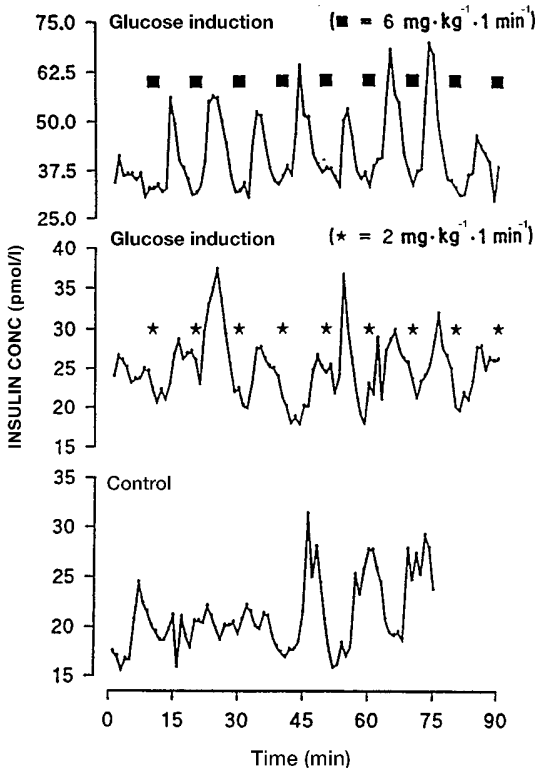

components of insulin secretion rates. In vivo, the insulin secretory rates are usually determined by use of deconvolution of peripheral insulin or C-peptide concentrations. The accuracy of estimated secretion could be improved by sampling from the portal vein. Inserting catheters into the portal vein upstream and downstream of the pancreatico duodenal vein in dogs has been used to directly measure crosspancreatic insulin changes (insulin secretion) (Fig. 4; Fig. 5). Combined with pulse detection analysis to allow separation of insulin release into basal and pulsatile release shows that at least $70 \%$ of all insulin is released during distinct punctuated insulin secretory bursts [69]. Application of a mathematically independent analysis, employing deconvolution of the portal-vein insulin concentration time series (using measured portal-vein insulin kinetics) confirms the estimate that at least $70 \%$ of insulin secretion arises from the pulsatile component of insulin secretion [69]. The similarities of portal-vein insulin concentration oscillations in dogs [27, 69] and humans [73] suggest a similar contribution in humans. After improvement of sampling techniques, insulin assays [122] and statistical analysis [35] a similar resolution from deconvolution of peripheral insulin concentration time series into mainly high frequency insulin secretory bursts and little (if any) non-pulsatile secretion is reported [35].

It therefore appears that in vivo, insulin secretion arises from a punctuate (likely Gaussian distributed) inter-islet coordinate high frequency $(\sim 5-8 \mathrm{~min} /$ pulse) series of secretory bursts, that dominates the overall insulin release. The similarity to in vitro secretory patterns indicates that the in vivo observed pattern is a summation of islet activity reported in vitro. 


\section{The neuronal control of in vivo pulsatile insulin secretion}

Observation of in vivo pulses implies that most betacells secrete in pulses and at the same time. In vitro studies on individual beta-cells show that they secrete in pulses [109], and that the pulsatile release pattern is probably linked to cyclic glycolysis [107], with cyclic generation of lactate [107], cyclic oxygen consumption [105], resulting in beta-cell depolarization through ATP-dependent potassium channels, causing influx of calcium, and subsequently (ATPdependent) exocytosis as reviewed in [112] and [123]. Thus the necessary mechanisms for the pulsatile release is within the individual beta-cells [112, 124], and the ability to act as pacemaker resides within the beta-cell [115]. A single islet consists of hundreds to a few thousands of individual beta-cells, along with $\alpha$-cells and $\delta$-cells. This cell population has also got a common and coordinate pulsatile release pattern of insulin [102, 105, 119, 125], and therefore intra-islet coordination of release from the individual beta cells must occur. This coordination could be through electro-physiological coupling among beta cells [126]. Studies on intracellular calcium show that an intra-islet spreading of the calcium influx is observed following an increase in intracellular calcium in a beta cell $[104,127,128]$. Alternatively, an agent that can diffuse between cells provides intra-islet synchronization of insulin release. Still an inter-islet coordinating mechanism is needed for in vivo pulsatile insulin secretion. The observation that insulin secretion from the isolated perfused pancreas is pulsatile has led to the hypothesis of an intra pancreatic pacemaker [9] that initiates the secretory pulses, probably through an extensive intra pancreatic neuronal network.

To examine the possible role of intrapancreatic nerves in regulating the coordination, various nerve blockers have been infused in the isolated perfused pancreas to observe whether pulsatile release pattern was disturbed. A significant impairment of the pulsatile release was observed when infusing post-synaptic nicotinic receptor antagonists (hexamethonium, $\alpha$ bungarotoxin, or curarine) in the isolated perfused pancreas [129], indicating an intra-pancreatic coordinating role of ganglionic nicotinic receptors. This is supported by the deterioration of pulsatile insulin release by infusion of the nerve blocker tetrodotoxin [116]. In addition, an intrinsic intra-islet neuronal controlling mechanism has been postulated based on increased frequency of insulin pulses from single islets exposed to tetrodotoxin [130]. The presence of preserved pulsatile insulin secretion after pancreas transplantation, albeit at increased frequency, further indicates the presence of an intra-pancreatic coordinating mechanism [75]. In vivo, cholinergic, alphaadrenergic and beta-adrenergic blocking agents did not perturb the detected periodicity in humans [131] or in monkeys [76], thus failing to support significance of these receptors on controlling pulsatile insulin release in vivo.

A different strategy has been the transplantation of islets into the liver, where re-enervation of islets is known to occur after 4 to 14 weeks $[132,133]$, to study the release pattern from islets dispersed throughout the liver at different times along the time-course of re-innervation [30]. In this study, 2000 islets were transplanted using the intra-hepatic method, by intra-portal injection, resulting in dispersed islets. Open loop perfusion studies on the insulin secretion from these islets were done at 2, 7, 28 and 200 days, and showed no coordinate release at 2 $(1 / 5)$ and 7 (0/5) days whereas, along with beginning re-innervation at 28 days, two out of five livers released insulin as coordinate pulses. In contrast, at fully established re-innervation all 12 livers released insulin as common coordinate insulin secretory bursts [30]. This indicates that innervation is a possible mechanism for intra-islet coordination.

In addition, the overall insulin secretion could be regulated by nerve blockers [76, 131] and neurotransmitters such as galanine [134], epinephrine [135, 136], GABA [137] dopamine [138], as well as nitric oxide [139], and because overall insulin release is pulsatile, the impact of these agents is probably involved in the regulation of pulses, although they have not been studied. In addition, sensory nerve blocking markedly increases insulin release [140], suggesting an inhibitory role of sensory nerves, and this could explain the loss of auto-feedback inhibition of insulin on insulin release in humans with pancreas transplant [141].

It appears that some intra-islet and inter-islet coordination is necessary for in vivo pulsatile insulin secretion, and that the intra-islet electro-physiological coupling provides a mechanism for the former, whereas intra-pancreatic neuronal coordination probably governs the inter-islet coordination. Therefore, the neuronal input probably has a pacemaker and coordinator function.

\section{Metabolic control of in vivo pulsatile insulin secretion}

The concept of the beta cell as a fuel sensor [142] imports significance to the mechanism by which glucose exerts its effects on the in vivo insulin release processing. In vitro studies suggest an increase in secretory burst mass by glucose with no impact on the secretory burst frequency $[115,118]$. Examining data on in vitro insulin release at increasing glucose concentrations indicate increasing pulsatile release, whereas the basal release could be constant and glucose-unaffected $[115,118]$. The mechanism by which glucose stimulates insulin release seems to involve cyclic glycolysis 
[105, 107], which generates oscillating intracellular concentrations of ATP [143], closure of ATP-dependent potassium channels and depolarization [120], increase in intracellular calcium [104, 105, 127], and subsequently an (ATP-dependent ?) exocytotic process. The cyclic glycolysis involves a positive feedback stimulation of phosphofructokinase by its product, fructose-1,6-biphosphate [112]. It seems plausible that similar mechanisms could be involved in vivo, as indicated from impaired pulsatile secretion in phosphofructokinase defects [144], implying that effects on secretory burst mass, but not frequency, are to expected. However, in dogs [27], the frequency of insulin secretory burst has been reported to increase with hyperglycaemia (7-8 min/pulse to $\sim 5 \mathrm{~min} /$ pulse), along with a much more pronounced increase in the secretory burst mass by us, whereas others find similar frequencies and marked increase in amplitude after, rather than before, meal ingestion [90]. The increase in frequency in vivo from 7-8 min/ pulse at basal state to $4-5 \mathrm{~min} /$ pulse at hyperglycaemia observed by us, compared with similar frequencies at different levels of hyperglycaemia ( $\sim 4$ minutes/pulse) observed in vitro could be due to an in vivo operating system dampening basal frequency to every 7-8 min per pulse, allowing the interval to shorten to every 4-5 min at hyperglycaemia. If this frequency dampening operating system is not present in vitro, this would explain the difference in frequency generally reported when comparing in vivo with in vitro release of insulin. In addition, because pulse detection ability could decrease with increasing pulse frequency, hyperglycaemia in Type II diabetes mellitus could be involved in the differences in detected pulsatile secretion. An interesting classic feed-back loop that involves glucose and insulin could also be involved in the generation of normal in vivo pulsatile insulin secretion, apart from the mechanisms described above. It has been shown that an ultradian oscillatory glucose infusion could entrain oscillatory insulin release [51]. In vitro studies on rapid entrainment show that even the rapid pulsatile insulin secretion could be induced by a rapid oscillatory glucose infusion in the isolated perfused rat pancreas [39], and in the isolated rat islets [102]. In vivo, a similar ability of punctuate glucose infusions to control pulsatile insulin secretion has been reported $[145,146]$. Studies using square wave infusions of modest doses of glucose $(6 \mathrm{mg} / \mathrm{kg} / \mathrm{min}$ over $1 \mathrm{~min})$ could induce a very pronounced pulsatile insulin release, with little or no breakthrough insulin secretion. Thus, the release process is entirely controlled by these rather small changes in circulating glucose concentration ( $\sim 0.3 \mathrm{mmol} / \mathrm{l})$ (Fig. 6). Furthermore, changes in frequency of the glucose induction control the frequency between 7 to 12 min per pulse [146]. This observation, that small doses of glucose could determine the frequency of pulsatile insulin release, seems contra-

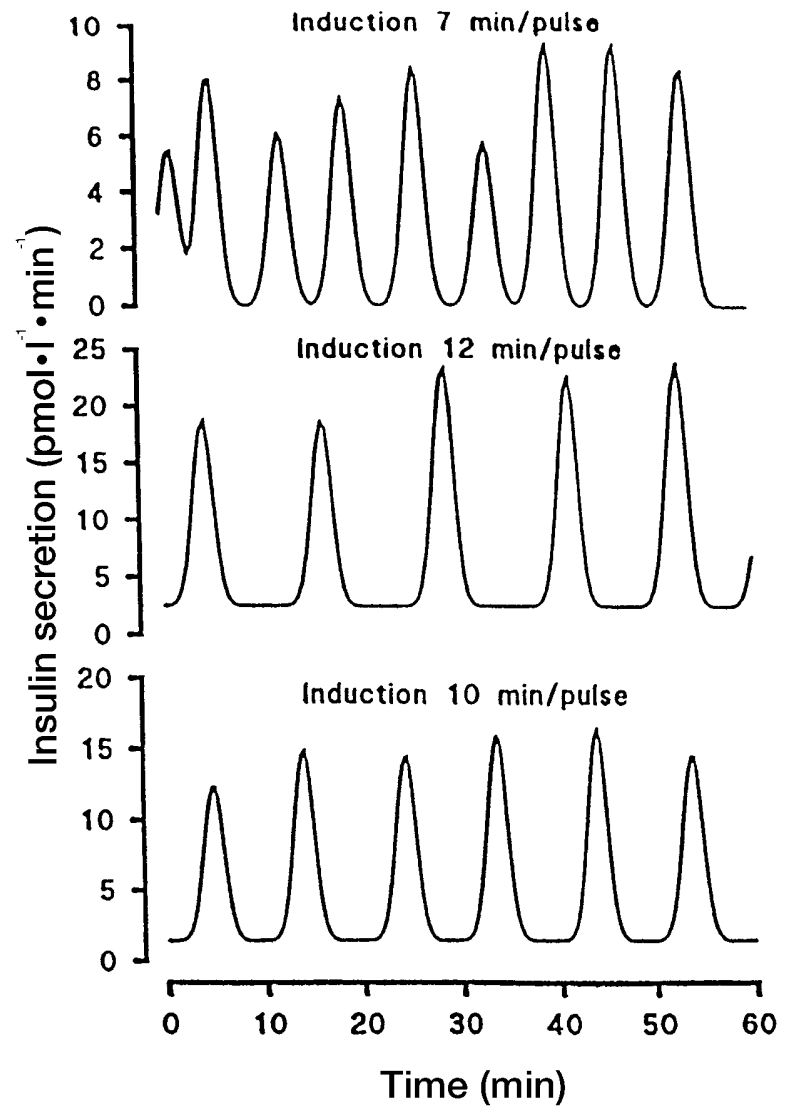

Fig. 6. Calculated (deconvolved) pulsatile insulin secretory rates when entraining insulin pulsatility by glucose infusion every 7 (top panel) 12 (middle panel) or 10 (bottom panel) min. Note again, the apparent minimal insulin secretion between pulses and that each glucose infusion is followed by an insulin pulse, in this case with no false positive or false negative pulses

dictory to the hypothesis of a pacemaker control that initiates the pulses. However, it appears possible that the hypothesized specialized neuronal pacemaker is also under the influence of glucose changes. This is supported by the observation that frequency increases with hyperglycaemia.

In addition to glucose, other nutrients such as amino acids and fatty acids are important for both insulin secretion and overall fuel homeostasis. Whereas the impact of various amino acids on overall insulin secretion has been studied, no studies have addressed the impact on pulsatility. Because the mechanism for stimulation could vary among amino acids, in vivo studies are further troubled as infusion of amino acids usually results in stimulation of growth hormone and glucagon secretion, which could exert confounding effects.

Non-esterified fatty acids are known to stimulate insulin secretion in vitro following short-term exposure, but inhibiting glucose-stimulated insulin release after long-term exposure [147]. Long chain non-esterfied fatty acids influence the release of insulin related to oxidation but also serve as a metabolic coupling 
factor (together with malonyl-CoA) for the regulation of glucose-stimulated insulin release $[143,148]$.

If non-esterified fatty acids potentiate the response of beta-cell secretory response to changes in glucose, an improved insulin release to glucose concentration feed back mechanism would be expected with increased concentrations of non-esterified fatty acids. In contrast, to the extent that non-esterified fatty acids compete with glucose for oxidation, an impaired ability to respond to glucose oscillations could occur. The pulsatile secretory pattern was preserved in obesity (with elevated non-esterified fatty acids), with similar relative amplitude of insulin oscillations [149], although a relation between waist-to-hip ratio and frequency of pulsatile insulin secretion suggests a role for the pulse frequency for insulin action [15].

Recent data on pulsatile insulin release in patients with Type II diabetes compared with healthy subjects, linked the orderliness of the release pattern estimated by approximate entropy, to the concentration of non-esterified fatty acids, and in both healthy subjects and in Type II diabetic individuals the release orderliness correlated positively with the concentrations of non-esterified fatty acids [150]. This, together with data in fasting and obesity, mentioned above, strongly suggest lipotoxicity is not a mechanism for impaired pulsatile release of insulin repeatedly reported in Type II diabetes, but could even suggest a role for non-esterified fatty acids to improve the pulsatile release pattern, possibly through improved sensitivity to oscillating glucose concentrations.

Non-esterified fatty acids also show an oscillatory pattern in dogs [151] and in humans [152]. This could provide a feedback mechanism for insulin to non-esterified fatty acid oscillatory coupling system. Using glucose infusions to induce pulsatile insulin secretory bursts at determined intervals shows independence of the oscillations in non-esterified fatty acids from insulin oscillations. Moreover, in long-term fasting there is a discrepancy between detected frequencies of 4 min per pulse for non-esterified fatty acids and 6-7 min for glucose and insulin. This indicates that there is probably another oscillatory system, possibly adrenergic/sympathetic, that controls the rapid changes in non-esterified fatty acids.

In addition, synchronous fluctuations have been shown of plasma insulin and lactate concentrations at a periodicity of about $85 \mathrm{~min}$ per oscillation.

\section{Hormonal control of in vivo pulsatile insulin secretion}

The pulsatile pattern of release seems to be important not only for insulin but also for the pituitary [100, 153, 154], adrenal [155] and parathyroid [156] hormones, for GLP-1 [157], leptin [158], and other islet hormones $[4,6,9,10,84]$. Because both growth hormone and the islet hormones are important for metabolic control, an interplay between the hormones might be necessary to optimize their release and action. Such interplay could involve actions on the secretory profiles of the other hormones in the same way as for IGF-1 on growth hormone [154]. Numerous hormones are important for controlling insulin release. Somatostatin secreting $\delta$-cells within the population of insulin secreting cells allows paracrine influence on insulin release. Somatostatin inhibits insulin secretion through the amount of insulin released per secretory burst, leading to reduced insulin pulses in the portal vein [28]. The latter seems to be important for the relative extraction of insulin in the liver. This probably reflects the binding of insulin to its receptors, because a linear relation of insulin amplitude to hepatic insulin extraction was observed [28]. In contrast, somatostatin has no impact on the frequency of secretory bursts, either at basal, or at postprandial conditions [28].

Like somatostatin, GLP-1 is a gut hormone, secreted upon luminal stimuli, and acting on beta cells to regulate the prandial insulin profile. It is a potent secretagogue that could become a future therapeutic agent for treatment of Type II diabetes. GLP-1 is considered a beta-cell glucose sensitizer that exerts actions together with increased glucose concentrations [159]. The mechanism for stimulating the release of insulin is through amplification of secretory burst mass which does not, however, affect the frequency and orderliness of the secretory process [34] (Fig.7). This is in line with the expected actions of a hormone that sensitizes the beta cell to glucose. It is important that a possible therapeutic agent does not impair pulsatility. Of possible therapeutic importance is the demonstration of preserved action in Type II diabetes with amplification of the insulin secretory burst mass at constant low dose infusion of GLP-1.

The pituitary-islet interaction is represented by IGF-1 that mediates growth hormone actions. The existence of IGF-1 receptors on beta cells suggests a role for IGF-1 in modulating insulin secretion, whereas inhibition of hepatic production of IGF-BP1 by insulin increases free IGF-1 concentrations, creating what seems to be a negative feedback loop between these structurally similar hormones. In humans, IGF-1 is shown to act on insulin secretion by inhibition of the secretory burst mass, and with no impact on secretory burst frequency [29], which is analogous to the effects of IGF-1 on pulsatile secretion of growth hormone [154].

Finally, angiotensin II suppresses insulin secretion by reducing insulin secretory burst mass without affecting the regularity as assessed by approximate entropy or the frequency [160]. Therefore, the hormones studied so far all exert their effects by regulating the secretory burst mass but numerous other hormones not studied could have different actions on the insulin release process. 


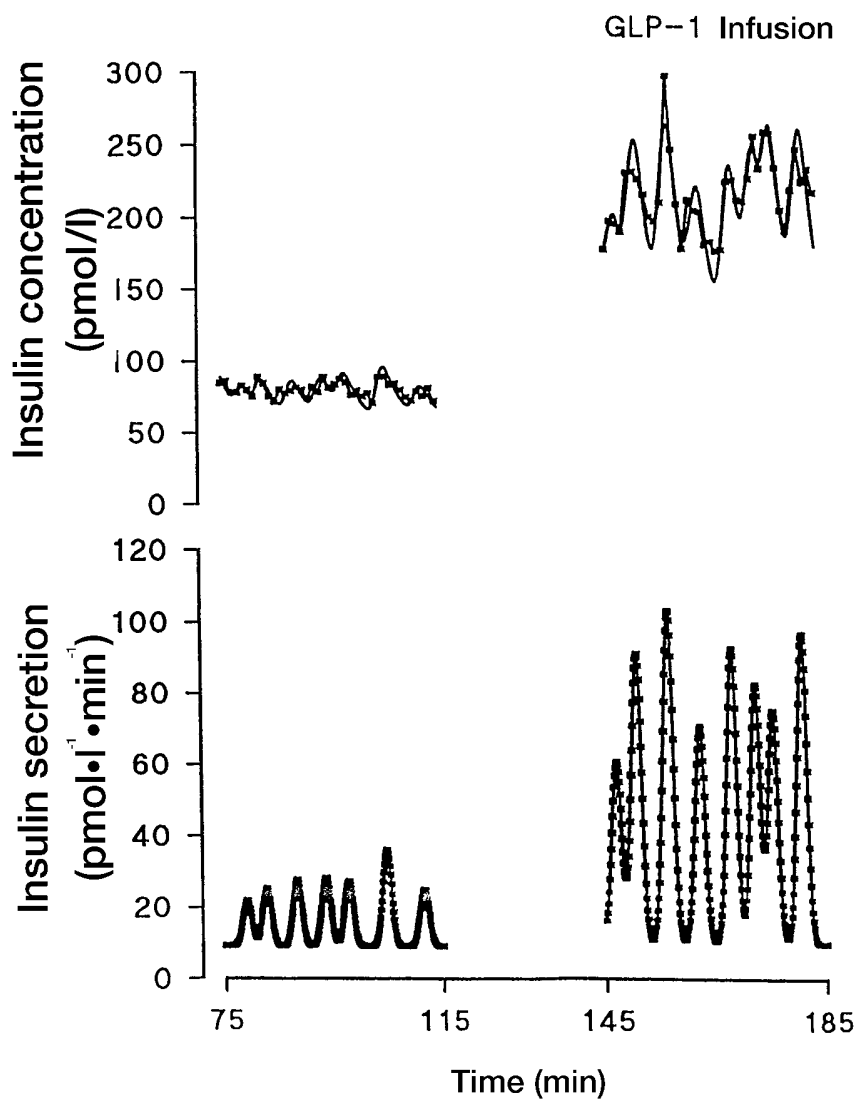

Fig. 7. An example of how overall insulin secretion is regulated via changes in the pulsatile component, in this case before (left panels) compared with during (right panels) infusion of the insulinotropic hormone GLP-1. The top panels show concentrations and best fit curves from deconvolution, whereas the bottom panels show calculated secretory rates. Note the massive amplification of the insulin secretory burst amplitude, with no apparent change in frequency

\section{Impact of drugs on insulin pulsatility}

Because pulsatile secretion could be important for both insulin action and beta-cell functions, the impact of sulphonylurea on the secretory pattern is important. In humans, an amplification of peripheral insulin oscillations with no change in frequency has been reported [131]. In a canine model, tolbutamide infusion results in a massive amplification of secretory burst mass with no effects on frequency or basal secretion and with no deterioration of the pulsatile pattern [32]. This seems important because a deterioration of the physiological release process is not desirable for a therapeutic agent for Type II diabetes, as mentioned for GLP-1 above. Of note, drugs that exert actions directly on the ATP-dependent potassium channels bypassing the glycolytic steps involved in pulsatile secretion, do not seem to impair the coordination of secretion of the about one million intra-pancreatically dispersed islets. The preserved or even improved pulsatile secretion during tolbutamide infu- sion strongly suggests that the in vivo coordinating mechanisms are strong and override the stimulus of individual islets. The influence of sulphonylurea is yet to be established in Type II diabetes. A novel non-sulphonylurea insulin secretagogue, repaglinide, as tolbutamide amplifies the secretory burst mass, without affecting the frequency of insulin oscillations [161]. Similarly, GLP-1 infusion in Type II diabetic individuals improves the secretory burst mass thus suggesting therapeutical options for improvement of pulsatile insulin release in Type II diabetes.

Other oral anti-diabetic drugs act as insulin sensitizers, reduce the insulin need and improve metabolic control. The effects of these drugs on insulin secretion are probably indirect but could mirror the influence of insulin resistance and metabolic control on beta-cell performance. No studies on these factors have been done but ultradian pulses have been shown to improve in periodicity in Type II diabetic patients treated with troglitazone [162]. Furthermore, in vitro studies on entrainment of rapid pulsatile secretion from pancreases of Zucker rats, clearly show improved responsiveness of the beta cells to the glucose oscillations by pioglitazone [38].

\section{Pulsatile insulin release in diabetes and prediabetes}

In Type II diabetes mellitus, the secretion of insulin is impaired, and this, together with insulin resistance, characterizes the metabolic derangement of the disease. The defective release of insulin involves reduced diurnal oscillations [57], impaired ultradian oscillations [49], and their reduced entrainment [46] as well as impaired rapid pulsatile secretion [37]. The resulting hypothesis of impaired insulin oscillations as a primary beta-cell defect in Type II diabetes was supported by the observation of defective oscillatory insulin release in first degree relatives of such patients [43]. Still, secretory dysfunction in both Type II diabetes and in glucose intolerance could be secondary to the glucose toxicity [2].

To further investigate if beta-cell dysfunction could be primary in Type II diabetes and parallel defects need to be identified in the complex cascade of metabolic events involved in pulsatile insulin secretion. To detect early defects, a test that examines subtle impairments seems necessary. It has to be superior to the intravenous glucose tolerance test that evaluates the response to a sudden rise in plasma glucose from about $5 \mathrm{mmol} / \mathrm{l}$ to $25 \mathrm{mmol} / \mathrm{l}$ [2]. Of note, increased disorderliness of insulin release accompanied by attenuated secretory burst mass is observed in older individuals, linking ageing to beta-cell dysfunction and suggesting that the defects that occur in Type II diabetes could be linked to ageing $[63,163]$.

Minimal repeated glucose infusions used to test for the adaptability of pulsatile insulin secretion to peri- 
odical trivial glucose excursions have been shown to improve markedly the ability to separate abnormal pulsatile insulin release in Type II diabetic individuals from that of matched control subjects by both autocorrelation analysis, spectral analysis, approximate entropy [164] and by spectral analysis [145]. These findings support the use of more refined methods for the prediction of apparent beta-cell dysfunction in Type II diabetes mellitus and genetically predisposed individuals, where more simple insulin secretion tests have little predictive value when using first phase insulin secretion [165]. The loss of regular pulsatile insulin patterns in Type II diabetes mellitus as well as in persons with slightly increased glucose concentrations could be due to an increase in frequency $[27,166]$ and a decrease in relative amplitude [31]. Similarly, increased frequency [167] as well as decreased regularity measured by approximate entropy [168] has been observed more frequently in obesity and in states of increasing insulin resistance [15].

\section{Conclusion}

The detection of high-frequency insulin oscillations corresponds to serial secretory insulin bursts. These bursts are the dominant mechanism for insulin secretion at basal states and the release of insulin is regulated through changes in frequency and/or mass of these secretory bursts. This secretory pattern is similar to that of the isolated pancreas, isolated islets and metabolic events in individual beta cells. The mechanism governing the coordination of in vivo pulsatile insulin secretion from the million islets scattered throughout the pancreas is believed to be neurogenic. However, the presence of plasma glucose oscillations preceding that of insulin indicates that glucose could control the pulsatile pattern in vivo, supported by entrainment of oscillatory insulin secretion in islets, the isolated perfused pancreas and in vivo in response to episodic glucose infusions.

Changes in the secratory pattern of insulin are of major importance in the development of Type II diabetes, either as a very early marker of beta-cell dysfunction, or as an aetiologically inherited beta-cell defect. The analysis of the mechanisms responsible for the development of pathological pulsatile insulin-secretory patterns of Type II diabetes should give a better insight into the causes of the beta-cell dysfunction in this disease and associated genetically inherited defects.

Sources. This review is based on the relevant literature published in English during the period 1922 to 2001. The sources available to the author were integrated with sources identified through PubMed searches, using searches for "insulin and oscillations", "insulin and pulsatility or pulsatile", "pulsatile secretion", "calcium oscillations", and "oscillations and secretion".

\section{References}

1. Hansen KM (1923) Oscillations in the blood sugar of fasting normal persons. Acta Endocrinol (Copenh)

2. Anderson GE, Kologlu Y, Papadopoulus C (1967) Fluctuations in Postabsorptive Blood Glucose In relation to Insulin Relase. Metabolism 16: 586-596

3. Koerker DJ, Goodner CJ, Hansen BW, Brown AC, Rubenstein AH (1978) Synchronous, sustained oscillation of C-peptide and insulin in the plasma of fasting monkeys. Endocrinology 102: 1649-1652

4. Lang DA, Matthews DR, Burnett M, Ward GM, Turner RC (1982) Pulsatile, synchronous basal insulin and glucagon secretion in man. Diabetes 31: 22-26

5. Lang DA, Matthews DR, Peto J, Turner RC (1979) Cyclic oscillations of basal plasma glucose and insulin concentrations in human beings. N Engl J Med 301: 1023-1027

6. Goodner CJ, Walike BC, Koerker DJ et al. (1977) Insulin, glucagon, and glucose exhibit synchronous, sustained oscillations in fasting monkeys. Science 195: 177-179

7. Goodner CJ, Hom FG, Koerker DJ (1982) Hepatic glucose production oscillates in synchrony with the islet secretory cycle in fasting rhesus monkeys. Science 215: $1257-1260$

8. Stagner J, Samols E (1988) Comparison of insulin and glucagon pulsatile secretion between the rat and dog pancreas in-vitro [published erratum appears in Life Sci (1989) 45: 463]. Life Sci 43: 929-934

9. Stagner JI, Samols E, Weir GC (1980) Sustained oscillations of insulin, glucagon, and somatostatin from the isolated canine pancreas during exposure to a constant glucose concentration. J Clin Invest 65: 939-942

10. Matthews DR, Hermansen K, Connolly AA et al. (1987) Greater in vivo than in vitro pulsatility of insulin secretion with synchronized insulin and somatostatin secretory pulses. Endocrinology 120: 2272-2278

11. Samols E, Stagner JI (1990) Islet somatostatin-microvascular, paracrine, and pulsatile regulation. Metabolism 39: $55-60$

12. Schmitz O, Pedersen SB, Mengel A et al. (1994) Augmented effect of short-term pulsatile versus continuous insulin delivery on lipid metabolism but similar effect on whole- body glucose metabolism in obese subjects. Metabolism 43: 842-846

13. Hunter SJ, Atkinson AB, Ennis CN, Sheridan B, Bell PM (1996) Association between insulin secretory pulse frequency and peripheral insulin action in NIDDM and normal subjects. Diabetes 45: 683-686

14. Engdahl JH, Veldhuis JD, Farrell PA (1995) Altered pulsatile insulin secretion associated with endurance training. J Appl Physiol 79: 1977-1985

15. Peiris AN, Stagner JI, Vogel RL, Nakagawa A, Samols E (1992) Body fat distribution and peripheral insulin sensitivity in healthy men: role of insulin pulsatility. J Clin Endocrinol Metab 75: 290-294

16. Paolisso G, Scheen AJ, Giugliano D et al. (1991) Pulsatile insulin delivery has greater metabolic effects than continuous hormone administration in man: importance of pulse frequency. J Clin Endocrinol Metab 72: 607-615

17. Paolisso G, Salvatore T, Sgambato S, Torella R, Varricchio M, D'Onofrio F (1990) Metabolic effects of pulsatile 
insulin infusion in the elderly. Acta Endocrinol (Copenh) 123: $19-23$

18. Paolisso G, Sgambato S, Passariello N, Scheen A, D’Onofrio F, Lefebvre PJ (1987) Greater efficacy of pulsatile insulin in type I diabetics critically depends on plasma glucagon levels. Diabetes 36: 566-570

19. Bratusch Marrain PR, Komjati M, Waldhäusl W (1987) Pulsatile insulin delivery: physiology and clinical implications. Diabet Med 4: 197-200

20. Ward GM, Walters JM, Aitken PM, Best JD, Alford FP (1990) Effects of prolonged pulsatile hyperinsulinemia in humans. Enhancement of insulin sensitivity. Diabetes 39: 501-507

21. Schmitz O, Arnfred J, Nielsen OH, Beck Nielsen H, Orskov H (1986) Glucose uptake and pulsatile insulin infusion: euglycaemic clamp and [3-3H]glucose studies in healthy subjects. Acta Endocrinol (Copenh) 113: 559-563

22. Paolisso G, Sgambato S, Gentile S et al. (1988) Advantageous metabolic effects of pulsatile insulin delivery in noninsulin-dependent diabetic patients. J Clin Endocrinol Metab 67: 1005-1010

23. Bratusch Marrain PR, Komjati M, Waldhäusl WK (1986) Efficacy of pulsatile versus continuous insulin administration on hepatic glucose production and glucose utilization in type I diabetic humans. Diabetes 35: 922-926

24. Matthews DR, Naylor BA, Jones RG, Ward GM, Turner RC (1983) Pulsatile insulin has greater hypoglycemic effect than continuous delivery. Diabetes 32: 617-621

25. Goodner CJ, Sweet IR, Harrison HCJ (1988) Rapid reduction and return of surface insulin receptors after exposure to brief pulses of insulin in perifused rat hepatocytes. Diabetes 37: 1316-1323

26. Porksen N, Munn S, Steers J, Vore S, Veldhuis J, Butler P (1995) Pulsatile insulin secretion accounts for $70 \%$ of total insulin secretion during fasting. Am J Physiol 269: E478-E488

27. Porksen N, Munn S, Steers J, Veldhuis JD, Butler PC (1996) Effects of glucose ingestion versus infusion on pulsatile insulin secretion. The incretin effect is achieved by amplification of insulin secretory burst mass. Diabetes 45: $1317-1323$

28. Porksen N, Munn SR, Steers JL, Veldhuis JD, Butler PC (1996) Effects of somatostatin on pulsatile insulin secretion: elective inhibition of insulin burst mass. Am J Physiol 270: E1043-E1049

29. Porksen N, Hussain MA, Bianda TL et al. (1997) IGF-I inhibits burst mass of pulsatile insulin secretion at supraphysiological and low IGF-I infusion rates. Am. J. Physiol 272: E352-E358

30. Porksen N, Munn S, Ferguson D, O'Brien T, Veldhuis J, Butler P (1994) Coordinate pulsatile insulin secretion by chronic intraportally transplanted islets in the isolated perfused rat liver. J. Clin. Invest 94: 219-227

31. Sturis J, O'Meara NM, Shapiro ET et al. (1993) Differential effects of glucose stimulation upon rapid pulses and ultradian oscillations of insulin secretion. J. Clin. Endocrinol. Metab 76: 895-901

32. Porksen NK, Munn SR, Steers JL, Schmitz O, Veldhuis JD, Butler PC (1996) Mechanisms of sulfonylurea's stimulation of insulin secretion in vivo: selective amplification of insulin secretory burst mass. Diabetes 45: 1792-1797

33. Hansen BC, Jen KL, Koerker DJ, Goodner CJ, Wolfe RA (1982) Influence of nutritional state on periodicity in plasma insulin levels in monkeys. Am J Physiol 242: R255-R260
34. Porksen N, Grofte B, Nyholm B et al. (1998) Glucagonlike peptide 1 increases mass but not frequency or orderliness of pulsatile insulin secretion. Diabetes 47: 45-49

35. Porksen N, Nyholm B, Veldhuis JD, Butler PC, Schmitz O (1997) In humans at least $75 \%$ of insulin secretion arises from punctuated insulin secretory bursts. Am J Physiol 273: E908-E914

36. Schmitz O, Porksen N, Nyholm B et al. (1997) Disorderly and nonstationary insulin secretion in relatives of patients with NIDDM. Am J Physiol 272: E218-E226

37. Lang DA, Matthews DR, Burnett M, Turner RC (1981) Brief, irregular oscillations of basal plasma insulin and glucose concentrations in diabetic man. Diabetes 30: 435-439

38. Sturis, J, Pugh WL, Tang J, Polonsky KS (1995) Prevention of diabetes does not completely prevent insulin secretory defects in the ZDF rat. Am J Physiol 269: E786-E792

39. Sturis J, Pugh WL, Tang J, Ostrega DM, Polonsky JS, Polonsky KS (1994) Alterations in pulsatile insulin secretion in the Zucker diabetic fatty rat. Am. J. Physiol 267: E250-E259

40. Paolisso G, Sgambato S, Torella R et al. (1988) Pulsatile insulin delivery is more efficient than continuous infusion in modulating islet cell function in normal subjects and patients with type 1 diabetes. J Clin Endocrinol Metab 66: 1220-1226

41. Bingley PJ, Matthews DR, Williams AJ, Bottazzo GF, Gale EA (1992) Loss of regular oscillatory insulin secretion in islet cell antibody positive non-diabetic subjects. Diabetologia 35: 32-38

42. Goodner CJ, Koerker DJ, Weigle DS, McCulloch DK (1989) Decreased insulin- and glucagon-pulse amplitude accompanying beta-cell deficiency induced by streptozocin in baboons. Diabetes 38: 925-931

43. O'Rahilly S, Turner RC, Matthews DR (1988) Impaired pulsatile secretion of insulin in relatives of patients with non-insulin-dependent diabetes. N Engl J Med 318: 1225-1230

44. Scheen AJ, Sturis J, Polonsky KS, Van Cauter E (1996) Alterations in the ultradian oscillations of insulin secretion and plasma glucose in aging. Diabetologia 39: 564-572

45. Polonsky KS, Sturis J, Bell GI (1996) Seminars in Medicine of the Beth Israel Hospital, Boston. Non- insulin-dependent diabetes mellitus - a genetically programmed failure of the beta cell to compensate for insulin resistance. N Engl J Med 334: 777-783

46. O'Meara NM, Sturis J, Van Cauter E, Polonsky KS (1993) Lack of control by glucose of ultradian insulin secretory oscillations in impaired glucose tolerance and in non-insulin- dependent diabetes mellitus. J Clin Invest 92: 262-271

47. Byrne MM, Sturis J, O’Meara NM, Polonsky KS (1995) Insulin secretion in insulin-resistant women with a history of gestational diabetes. Metabolism 44: 1067-1073

48. Ehrmann DA, Sturis J, Byrne MM, Karrison T, Rosenfield RL, Polonsky KS (1995) Insulin secretory defects in polycystic ovary syndrome. Relationship to insulin sensitivity and family history of non- insulin-dependent diabetes mellitus. J Clin Invest 96: 520-527

49. Sturis J, Polonsky KS, Shapiro ET, Blackman JD, O’Meara NM, Van Cauter E (1992) Abnormalities in the ultradian oscillations of insulin secretion and glucose levels in Type II (non-insulin-dependent) diabetic patients. Diabetologia 35: 681-689

50. Simon C, Brandenberger G, Follenius M (1987) Ultradian oscillations of plasma glucose, insulin, and C-peptide in 
man during continuous enteral nutrition. J Clin Endocrinol Metab 64: 669-674

51. Sturis J, Van Cauter E, Blackman JD, Polonsky KS (1991) Entrainment of pulsatile insulin secretion by oscillatory glucose infusion. J Clin Invest 87: 439-445

52. Sturis J, Scheen AJ, Leproult R, Polonsky KS, Van Cauter E (1995) 24-hour glucose profiles during continuous or oscillatory insulin infusion. Demonstration of the functional significance of ultradian insulin oscillations. J Clin Invest 95: 1464-1471

53. O'Meara NM, Sturis J, Herold KC, Ostrega DM, Polonsky KS (1995) Alterations in the patterns of insulin secretion before and after diagnosis of IDDM. Diabetes Care 18: $568-571$

54. Van Cauter E, Shapiro ET, Tillil H,Polonsky KS (1992) Circadian modulation of glucose and insulin responses to meals: relationship to cortisol rhythm. Am J Physiol 262: E467-E475

55. Van Cauter E, Blackman JD, Roland D, Spire JP, Refetoff S, Polonsky KS (1991) Modulation of glucose regulation and insulin secretion by circadian rhythmicity and sleep. J Clin Invest 88: 934-942

56. Shapiro ET, Tillil H, Polonsky KS, Fang VS, Rubenstein AH, Van Cauter E (1988) Oscillations in insulin secretion during constant glucose infusion in normal man: relationship to changes in plasma glucose. J Clin Endocrinol Metab 67: 307-314

57. Polonsky KS, Given BD, Hirsch LJ et al. (1988) Abnormal patterns of insulin secretion in non-insulin-dependent diabetes mellitus. N Engl J Med 318: 1231-1239

58. Polonsky KS, Given BD, Van Cauter E (1988) Twentyfour-hour profiles and pulsatile patterns of insulin secretion in normal and obese subjects. J Clin Invest 81: $442-448$

59. Komjati M, Bratusch Marrain P, Waldhäusl W (1986) Superior efficacy of pulsatile versus continuous hormone exposure on hepatic glucose production in vitro. Endocrinology 118: 312-319

60. Paolisso G, Scheen AJ, Verdin EM, Luyckx AS, Lefebvre PJ (1986) Insulin oscillations per se do not affect glucose turnover parameters in normal man. $\mathrm{J}$ Clin Endocrinol Metab 63: 520-525

61. Matthews DR (1991) Physiological implications of pulsatile hormone secretion. Ann NY Acad Sci 618: 28-37

62. Wiggam MI, Hunter SJ, Armstrong VL et al. (2000) Insulin resistance and insulin pulsatility in essential hypertension. J Hypertens 18: 743-748

63. Meneilly GS, Veldhuis JD, Elahi D (1999) Disruption of the pulsatile and entropic modes of insulin release during an unvarying glucose stimulus in elderly individuals. J Clin Endocrinol Metab 84: 1938-1943

64. Meneilly GS, Ryan AS, Veldhuis JD, Elahi D (1997) Increased disorderliness of basal insulin release, attenuated insulin secretory burst mass, and reduced ultradian rhythmicity of insulin secretion in older individuals. J Clin Endocrinol Metab 82: 4088-4093

65. Eaton RP, Friedman N, Allen RC, SchadeDS (1984) Insulin removal in man: in vivo evidence for a receptor-mediated process. J Clin Endocrinol Metab 58: 555-559

66. Eaton RP, Allen RC, Schade DS (1983) Hepatic removal of insulin in normal man: dose response to endogenous insulin secretion. J Clin Endocrinol Metab 56: 1294-1300

67. Jaspan J, Polonsky K (1982) Glucose ingestion in dogs alters the hepatic extraction of insulin. J Clin Invest 69 : 516-525

68. Ishida T, Chou J, Lewis RM, Hartleay CJ, Entman M, Field JB (1983) The effect of ingestion of meat on hepatic extraction of insulin and glucagon and hepatic glucose output in conscious dogs. Metabolism 32: 558-567

69. Porksen N, Munn S, Steers J, Veldhuis JD, Butler PC (1995) Impact of sampling technique on appraisal of pulsatile insulin secretion by deconvolution and cluster analysis. Am J Physiol 269: E1106-E1114

70. Valdeolmillos M, Gomis A, Sanchez Andres JV (1996) In vivo synchronous membrane potential oscillations in mouse pancreatic beta-cells: lack of co-ordination between islets. J Physiol (Lond) 493: 9-18

71. Jaspan JB, Lever E, Polonsky KS, Van Cauter E (1986) In vivo pulsatility of pancreatic islet peptides. Am J Physiol 251: E215-E226

72. Song SH, McIntyre SS, Shah H, Veldhuis JD, Hayes PC, Butler PC (2000) Direct measurement of pulsatile insulin secretion from the portal vein in human subjects. J Clin Endocrinol Metab 85: 4491-4499

73. Storch MJ, Rossle M, Kerp L (1993) Pulsatile insulin secretion into the portal vein in liver cirrhosis. Dtsch Med Wochenschr 118: 134-138

74. O'Meara NM, Sturis J, Blackman JD, Van Cauter E, Polonsky KS (1993) Analytical problems in detecting rapid insulin secretory pulses in normal humans. Am J Physiol 264: E231-E238

75. O'Meara NM, Sturis J, Blackman JD, Byrne MM, Jaspan JB, Thistlethwaite JR, Polonsky KS (1993) Oscillatory insulin secretion after pancreas transplant. Diabetes 42 : 855-861

76. Hansen BC, Pek S, Koerker DJ, Goodner CJ, Wolfe RA, Schielke GP (1981) Neural influences on oscillations in basal plasma levels of insulin in monkeys. Am J Physiol 240: E5-E11

77. Horwitz DL, Starr JI, Mako ME, Blackard WG, Rubenstein AH (1975) Proinsulin, insulin, and C- peptide concentrations in human portal and peripheral blood. J Clin Invest 55: 1278-1283

78. Jaspan J, Polonsky K (1982) Glucose ingestion in dogs alters the hepatic extraction of insulin. In vivo evidence for a relationship between biologic action and extraction of insulin. J Clin Invest 69: 516-525

79. Morishima T, Bradshaw C, Radziuk J (1985) Measurement using tracers of steady-state turnover and metabolic clearance of insulin in dogs. Am J Physiol 248: E203-E208

80. Ferrannini E, Wahren J, Faber OK, Felig P, Binder C, DeFronzo RA (1983) Splanchnic and renal metabolism of insulin in human subjects: a dose- response study. Am J Physiol 244: E517-E527

81. Duckworth WC (1988) Insulin degradation: mechanisms, products, and significance. Endocr Rev 9: 319-345

82. Polonsky K, Jaspan J, Pugh W et al. (1983) Metabolism of C-peptide in the dog. In vivo demonstration of the absence of hepatic extraction. J Clin Invest 72: 1114-1123

83. Van Cauter E, Mestrez F, Sturis J, Polonsky KS (1992) Estimation of insulin secretion rates from $\mathrm{C}$ - peptide levels. Comparison of individual and standard kinetic parameters for C- peptide clearance. Diabetes 41: 368-377

84. Juhl CB, Porksen N, Sturis J et al. (2000) High- frequency oscillations in circulating amylin concentrations in healthy humans. Am J Physiol Endocrinol Metab 278: E484-E490

85. Beer SF, O'Rahilly S, Spivey RS, Hales CN, Turner RC (1990) Plasma proinsulin in first-degree relatives of type 2 diabetic subjects. Diabetes Res 14: 51-54

86. Porte DJ, Kahn SE (1989) Hyperproinsulinemia and amyloid in NIDDM. Clues to etiology of islet beta-cell dysfunction? Diabetes 38: 1333-1336

87. Christiansen E, Roder M, Tibell A, Hales CN, Madsbad S (1998) Effect of pancreas transplantation and immuno- 
suppression on proinsulin secretion. Diabet Med 15: 739-746

88. Stagner J, Nakagawa A, Peiris A, Samols E, Vogel R (1992) Islet hormone pulse intervals are dependent upon sampling frequency. Life Sci 50: 769-774

89. Veldhuis JD, Johnson ML (1986) Cluster analysis: a simple, versatile, and robust algorithm for endocrine pulse detection. Am J Physiol 250: E486-E493

90. Balks HJ, Schmidt A, Prank K, Hemmer F, von zur Muhlen A, Brabant G (1992) Temporal pattern of pancreatic insulin and C-peptide secretion and of plasma glucose levels after nutritional stimulation. J Clin Endocrinol Metab 75: 1198-1203

91. Blackman JD, Polonsky KS, Jaspan JB, Sturis J, Van Cauter E, Thistlethwaite JR (1992) Insulin secretory profiles and C-peptide clearance kinetics at 6 months and 2 years after kidney-pancreas transplantation. Diabetes 41: 1346-1354

92. Pincus SM (1991) Approximate entropy as a measure of system complexicity. Proc Natl Acad Sci USA 88: 2297-2301

93. Pincus S, Singer BH (1998) A recipe for randomness Proc Natl Acad Sci USA 95: 10367-10372

94. Pincus SM, Keefe DL (1992) Quantification of hormone pulsatility via an approximate entropy algorithm. Am J Physiol 262: E741-E7-54

95. Hartman ML, Pincus SM, Johnson ML et al. (1994) Enhanced basal and disorderly growth hormone secretion distinguish acromegalic from normal pulsatile growth hormone release. J Clin Invest 94: 1277-1288

96. Pincus SM, Mulligan T, Iranmanesh A, Gheorghiu S, Godschalk M, Veldhuis JD (1996) Older males secrete luteinizing hormone and testosterone more irregularly, and jointly more asynchronously, than younger males. Proc Natl Acad Sci USA 93: 14100-14105

97. Siragy HM, Vieweg WV, Pincus S, Veldhuis JD (1995) Increased disorderliness and amplified basal and pulsatile aldosterone secretion in patients with primary aldosteronism. J Clin Endocrinol Metab 80: 28-33

98. van den Berg G, Pincus SM, Veldhuis JD, Frolich M, Roelfsema F (1997) Greater disorderliness of ACTH and cortisol release accompanies pituitary-dependent Cushing's disease. Eur J Endocrinol 136: 394-400

99. Roelfsema F, Pincus SM, Veldhuis JD (1998) Patients with Cushing's disease secrete adrenocorticotropin and cortisol jointly more asynchronously than healthy subjects. J Clin Endocrinol Metab 83: 688-692

100. Veldhuis JD, Carlson ML, Johnson ML (1987) The pituitary gland secretes in bursts: appraising the nature of glandular secretory impulses by simultaneous multipleparameter deconvolution of plasma hormone concentrations. Proc Natl Acad Sci USA 84: 7686-7690

101. Goodner CJ, Koerker DJ, Stagner JI, Samols E (1991) In vitro pancreatic hormonal pulses are less regular and more frequent than in vivo. Am J Physiol 260: E422-E429

102. Chou HF, Ipp E (1990) Pulsatile insulin secretion in isolated rat islets. Diabetes 39: 112-117

103. Hayek A, (1981) Preservation of insulin release periodicity from individual islets of obese Zucker rats. Horm Metab Res 13: 119-120

104. Santos RM, Rosario LM, Nadal A, Garcia Sancho J, Soria B, Valdeolmillos M (1991) Widespread synchronous $[\mathrm{Ca} 2+] \mathrm{i}$ oscillations due to bursting electrical activity in single pancreatic islets. Pflugers Arch 418: 417-422

105. Longo EA, Tornheim K, Deeney JT, Varnum BA, Tillotson D, Prentki M, Corkey BE (1991) Oscillations in cytosolic free $\mathrm{Ca} 2+$, oxygen consumption, and insulin secre- tion in glucose-stimulated rat pancreatic islets. J Biol Chem 266: 9314-9319

106. Cook DL (1983) Isolated islets of Langerhans have slow oscillations of electrical activity. Metabolism 32: $681-685$

107. Chou HF, Berman N, Ipp E (1992) Oscillations of lactate released from islets of Langerhans: evidence for oscillatory glycolysis in beta-cells. Am J Physiol 262: E800-E805

108. Bergsten P (1995) Slow and fast oscillations of cytoplasmic $\mathrm{Ca} 2+$ in pancreatic islets correspond to pulsatile insulin release. Am J Physiol 268: E282-E287

109. Hellman B, Gylfe E, Bergsten P et al. (1994) Glucose induces oscillatory $\mathrm{Ca} 2+$ signalling and insulin release in human pancreatic beta cells. Diabetologia 37 [Suppl 2]: S11-S20

110. Hellman B, Gylfe E, Grapengiesser E, Lund PE, Berts A (1992) Cytoplasmic Ca2 + oscillations in pancreatic betacells. Biochim Biophys Acta 1113: 295-305

111. Gylfe E, Grapengiesser E, Hellman B (1991) Propagation of cytoplasmic $\mathrm{Ca} 2+$ oscillations in clusters of pancreatic beta-cells exposed to glucose. Cell Calcium 12: 229-240

112. Tornheim K (1997) Are metabolic oscillations responsible for normal oscillatory insulin secretion? Diabetes 46: $1375-1380$

113. Berman N, Chou HF, Berman A, Ipp E (1993) A mathematical model of oscillatory insulin secretion. Am J Physiol 264: R839-R851

114. Sherman A (1996) Contributions of modeling to understanding stimulus-secretion coupling in pancreatic betacells. Am J Physiol 271: E362-E372

115. Cunningham BA, Deeney JT, Bliss CR, Corkey BE, Tornheim K (1996) Glucose-induced oscillatory insulin secretion in perifused rat pancreatic islets and clonal beta-cells (HIT). Am J Physiol 271: E702-E710

116. Stagner JI, Samols E (1985) Perturbation of insulin oscillations by nerve blockade in the in vitro canine pancreas. Am J Physiol 248: E516-E521

117. Westerlund J, Hellman B, Bergsten P (1996) Pulsatile insulin release from mouse islets occurs in the absence of stimulated entry of Ca2 + . J Clin Invest 97: 1860-1863

118. Bergsten P, Hellman B (1993) Glucose-induced amplitude regulation of pulsatile insulin secretion from individual pancreatic islets. Diabetes 42: 670-674

119. Marchetti P, Scharp DW, Mclear M et al. (1994) Pulsatile insulin secretion from isolated human pancreatic islets. Diabetes 43: 827-830

120. Rosario LM, Atwater I, Scott AM (1986) Pulsatile insulin release and electrical activity from single ob/ob mouse islets of Langerhans. Adv Exp Med Biol 211: 413-425

121. Chou HF, McGivern R, Berman N, Ipp E (1991) Oscillations of circulating plasma insulin concentrations in the rat. Life Sci 48: 1463-1469

122. Andersen L, Dinesen B, Jorgensen PN, Poulsen F, Roder ME (1993) Enzyme immunoassay for intact human insulin in serum or plasma. Clin Chem 39: 578-582

123. Misler S, Barnett DW, Gillis KD, Pressel DM (1992) Electrophysiology of stimulus-secretion coupling in human beta-cells. Diabetes 41: 1221-1228

124. Palti Y, David GB, Lachov E, Mida YH, Schatzberger R (1996) Islets of Langerhans generate wavelike electric activity modulated by glucose concentration. Diabetes 45 : 595-601

125. Bergsten P, Grapengiesser E, Gylfe E, Tengholm A, Hellman B (1994) Synchronous oscillations of cytoplasmic $\mathrm{Ca} 2+$ and insulin release in glucose-stimulated pancreatic islets. J Biol Chem 269: 8749-8753 
126. Meissner HP (1976) Electrophysiological evidence for coupling between beta cells of pancreatic islets. Nature 262: 502-504

127. Gilon P, Henquin JC (1992) Influence of membrane potential changes on cytoplasmic $\mathrm{Ca} 2+$ concentration in an electrically excitable cell, the insulin- secreting pancreatic B-cell. J Biol Chem 267: 20713-20720

128. Valdeolmillos M, Nadal A, Soria B, Garcia-Sancho J (1993) Fluorescence digital image analysis of glucose-induced $[\mathrm{Ca} 2+] \mathrm{i}$ oscillations in mouse pancreatic islets of Langerhans. Diabetes 42: 1210-1214

129. Stagner JI, Samols E (1985) Role of intrapancreatic ganglia in regulation of periodic insular secretions. Am J Physiol 248: E522-E530

130. Opara EC, Go VL (1991) Effect of nerve blockade on pulsatile insulin and glucagon secretion in vitro. Pancreas 6: 653-658

131. Matthews DR, Lang DA, Burnett MA, Turner RC (1983) Control of pulsatile insulin secretion in man. Diabetologia 24: 231-237

132. Griffith RC, Scharp DW, Hartman BK, Ballinger WF, Lacy PE (1977) A morphologic study of intrahepatic portal-vein islet isografts. Diabetes 26: 201-214

133. Korsgren O, Jansson L, Andersson A, Sundler F, (1993) Reinnervation of transplanted pancreatic islets. A comparison among islets implanted into the kidney, spleen, and liver. Transplantation 56: 138-143

134. Hermansen K (1988) Effects of galanin on the release of insulin, glucagon and somatostatin from the isolated, perfused dog pancreas. Acta Endocrinol (Copenh) 119: 91-98

135. Campfield LA, Smith FJ (1983) Neural control of insulin secretion: interaction of norepinephrine and acetylcholine. Am J Physiol 244: R629-R634

136. Natali A, Gastaldelli A, Galvan AQ et al. (1998) Effects of acute alpha 2-blockade on insulin action and secretion in humans. Am J Physiol 274: E57-E64

137. Kawai Unger RH (1983) Effects of gamma-aminobutyric acid on insulin, glucagon, and somatostatin release from isolated perfused dog pancreas. Endocrinology 113: 111-113

138. Arneric SP, Chow SA, Long JP, Fischer LJ (1984) Inhibition of insulin release from rat pancreatic islets by drugs that are analogues of dopamine. Diabetes 33: 888-893

139. Shankar R, Zhu JS, Ladd B, Henry D, Shen HQ, Baron AD (1998) Central nervous system nitric oxide synthase activity regulates insulin secretion and insulin action. J Clin Invest 102: 1403-1412

140. Karlsson S, Scheurink AJ, Steffens AB, Ahren B (1994) Involvement of capsaicin-sensitive nerves in regulation of insulin secretion and glucose tolerance in conscious mice. Am J Physiol 267: R1071-R1077

141. Luzi L, Battezzati A, Perseghin G et al. (1992) Lack of feedback inhibition of insulin secretion in denervated human pancreas. Diabetes 41: 1632-1639

142. Rorsman P (1997) The pancreatic beta-cell as a fuel sensor: an electrophysiologist's viewpoint. Diabetologia 40: 487-495

143. Prentki M, Vischer S, Glennon MC, Regazzi R, Deeney JT, Corkey BE (1992) Malonyl-CoA and long chain acylCoA esters as metabolic coupling factors in nutrient-induced insulin secretion. J Biol Chem 267: 5802-5810

144. Ristow M, Carlqvist H, Hebinck J et al. (1999) Deficiency of phosphofructo-1-kinase/muscle subtype in humans is associated with impairment of insulin secretory oscillations. Diabetes 48: 1557-1561

145. Mao CS, Berman N, Roberts K, Ipp E (1999) Glucose entrainment of high-frequency plasma insulin oscillations in control and type 2 diabetic subjects. Diabetes 48 : 714-721

146. Porksen N, Juhl C, Hollingdal M et al. (2000) Concordant induction of rapid in vivo pulsatile insulin secretion in healthy humans by recurrent punctuated glucose infusions. Am J Physiol 278: E162-E170

147. Zhou YP, Grill VE (1994) Long-term exposure of rat pancreatic islets to fatty acids inhibits glucose- induced insulin secretion and biosynthesis through a glucose fatty acid cycle. J Clin Invest 93: 870-876

148. McGarry JD, Dobbins RL (1999) Fatty acids, lipotoxicity and insulin secretion. Diabetologia 42: 128-138

149. Sonnenberg GE, Hoffman RG, Mueller RA, Kissebah AH (1994) Splanchnic insulin dynamics and secretion pulsatilities in abdominal obesity. Diabetes 43: 468-477

150. Schmitz O, Juhl CB, Hollingdal M, Veldhuis JD, Porksen N, Pincus SM (2001) Irregular circulating insulin concentrations in type 2 diabetes mellitus: an inverse relationship between circulating free fatty acid and the disorderliness of an insulin time series in diabetic and healthy individuals. Metabolism 50: 41-46

151. Getty L, Panteleon AE, Mittelman SD, Dea MK, Bergman RN (2000) Rapid oscillations in omental lipolysis are independent of changing insulin levels in vivo. J Clin Invest 106: 421-430

152. Porksen N, Juhl C, Schmitz O (1999) Oscillating concentrations of free fatty acids independent of insulin and glucose oscillations. Diabetologia 42 [Suppl I]: A45 (Abstract)

153. Brabant G, Prank K, Hoang-Vu C, Hesch RD, von zur Muhlen A (1991) Hypothalamic regulation of pulsatile thyrotopin secretion. J Clin Endocrinol Metab 72:145-150

154. Bermann M, Jaffe CA, Tsai W, DeMott Friberg R, Barkan AL (1994) Negative feedback regulation of pulsatile growth hormone secretion by insulin-like growth factor I. Involvement of hypothalamic somatostatin. J Clin Invest 94: $138-145$

155. Schofl C, Becker C, Prank K, von zur Muhlen A, Brabant G (1997) Twenty-four-hour rhythms of plasma catecholamines and their relation to cardiovascular parameters in healthy young men. Eur J Endocrinol. 137: 675-683

156. Prank K, Nowlan SJ, Harms HM et al. (1995) Time series prediction of plasma hormone concentration. Evidence for differences in predictability of parathyroid hormone secretion between osteoporotic patients and normal controls. J Clin Invest 95: 2910-2919

157. Balks HJ, Holst JJ, von zur Muhlen A, Brabant G (1997) Rapid oscillations in plasma glucagon-like peptide-1 (GLP-1) in humans: cholinergic control of GLP-1 secretion via muscarinic receptors. J Clin Endocrinol Metab 82: 786-790

158. Sinha MK, Sturis J, Ohannesian J et al. (1996) Ultradian oscillations of leptin secretion in humans. Biochem Biophys Res Commun 228: 733-738

159. Holz GG, Kuhtreiber WM, Habener JF (1993) Pancreatic beta-cells are rendered glucose-competent by the insulinotropic hormone glucagon-like peptide-1(7-37). Nature 361: 362-365

160. Fliser D, Schaefer F, Schmid D, Veldhuis JD, Ritz E (1997) Angiotensin II affects basal, pulsatile, and glucose-stimulated insulin secretion in humans. Hypertension 30: 1156-1161

161. Juhl C, Porksen N, Sturis J et al. (1999) Repaglinide amplifies insulin secretory burst mass without affecting burst frequency. Diabetologia 42 [Suppl 1]: A4-A4

162. Cavaghan MK, Ehrmann DA, Byrne MM, Polonsky KS (1997) Treatment with the oral antidiabetic agent trogli- 
tazone improves beta cell responses to glucose in subjects with impaired glucose tolerance. J Clin Invest 100: 530-537

163. Meneilly GS, Elahi D (1998) Physiological importance of first-phase insulin release in elderly patients with diabetes. Diabetes Care 21: 1326-1329

164. Hollingdal M, Juhl C, Porksen N et al. (1999) Glucose pulse induction markedly improves detection of a disrupted oscillatory insulin secretion in Type II diabetes. Diabetologia 42 [Suppl 1]: A78-A78

165. Christiansen E, Tibell A, Volund A et al. (1996) Pancreatic endocrine function in recipients of segmental and whole pancreas transplantation. J Clin Endocrinol Metab 81: 3972-3979

166. Matthews DR (1996) Oscillatory insulin secretion: a variable phenotypic marker. Diabet Med 13: S53-S58

167. Radetti G, Ghizzoni L, Paganini C, Iughetti L, Caselli G, Bernasconi S (1998) Insulin pulsatility in obese and normal prepubertal children. Horm Res 50: 78-82

168. Zarkovic M, Ciric J, Stojanovic M et al. (1999) Effect of insulin sensitivity on pulsatile insulin secretion. Eur J Endocrinol 141: 494-501 